Article

\title{
Integrated Evaluation of the Impediments to the Adoption of Coconut Palm Wood as a Sustainable Material for Building Construction
}

\author{
Mahmoud Sodangi * and Zaheer Abbas Kazmi \\ Department of Civil \& Construction Engineering, College of Engineering, Imam Abdulrahman Bin \\ Faisal University, Dammam 31441, Saudi Arabia; zakazmi@iau.edu.sa \\ * Correspondence: misodangi@iau.edu.sa
}

Received: 18 August 2020; Accepted: 15 September 2020; Published: 17 September 2020

\begin{abstract}
Coconut palm wood is commonly regarded as a sustainable building material. Nonetheless, its adoption as a green building material by the construction industry is limited, particularly in West Africa. This paper analyses the impediments to the effective adoption of coconut palm wood in residential building construction. The research data was collected from literature reviews, expert-based surveys, and semi-structured interviews with specialists from the construction sector, African Timber Organization, governmental institutions related to forestry and construction, university professors, and researchers in the areas of sustainable building materials and construction. Thirteen crucial impediments were identified and an integrated evaluation of the impediments was conducted using the Interpretive Structural Modelling (ISM) technique to examine the hierarchical structure of the relations between the impediments. A further technique, Cross-impact Matrix Multiplication Applied to Classification (MICMAC), was used to categorize the impediments from a driving to driven perspective. This categorization provides a unique profile for the impediments, which is different from that of conventional evaluation techniques for evaluating impediments. The findings of this paper offer useful guide to practitioners and policy makers in formulating effective policies, regulations, and standards that will promote the development and wide adoption of coconut palm wood in the construction industry.
\end{abstract}

Keywords: coconut palm wood; impediments; sustainable construction; sustainable material; building construction

\section{Introduction}

West Africa is the region with the largest number of countries and the most populous one in Africa, with an estimated 400 million people in 2020. Despite the incessant socio-political turmoil, insecurity and socio-economic challenges bedeviling the region, countries in the region face grave housing deficits [1]. Of the 15 member countries in the region, Nigeria presents the greatest housing deficit (17 million housing units) as the country accounts for more than half of West Africa's population [2]. Several factors explain the large housing deficits observed in the region. Endogenous population growth and rapid urbanization fueled by rural to urban migration are further raising the demand for housing [3]. However, as Bah et al. [1] have pointed out, the supply of housing has been insufficient for several reasons. First, poor urban planning is hampering urban expansion through limited supply of land and infrastructure. Second, multiple land tenure regimes, and inadequate land administration and governance systems contribute to land tenure insecurity and the high costs of urban land. Third, underdeveloped housing finance markets imply that most Africans can only rely on self-financing and incremental construction mechanisms to acquire 
housing [4]. Above all, high construction costs make housing unaffordable to the majority of low and middle-income households.

While the huge housing deficits ultimately leads to incessant high demand for building materials, the need for increased availability of non-traditional construction materials ultimately brings about increased carbon emissions, which will affect the availability of existing natural resources [5]. To significantly decrease the housing deficits, huge costs of construction, and the negative effect of non-traditional construction materials on the built environment, attention must be shifted to the use of traditional building materials in modern methods of construction [6]. The adoption of locally accessible traditional materials in building construction is a potential to be thoroughly investigated. One particular green building material with huge appealing potential for the West African building sector is coconut palm wood. However, the use of coconut palm wood in the region's construction sector has been mostly constrained to non-load-bearing functions and in some few cases, in rural communities. In the urban spheres, the use of concrete and steel is more preferred as they are widely regarded as being more sophisticated, safe, easy to repair and maintain. Traditional coconut palm wood has never been subject to a strategic analysis to examine the potential of its full utilization in the building sector, particularly in urban areas. Remarkably, coconut palm wood is highly strong and durable [7]. It could as well be fully utilized in building construction to save costs. Coconut palm wood is relatively cheaper in the market than the typical timber used for structural functions in building construction $[7,8]$. Other prominent features of coconut palm wood include its lightweight nature, large-scale availability in West Africa, and most importantly, its environmental friendliness.

Considering these outstanding benefits of using coconut wood as a sustainable material for building construction, as well as the alarming housing deficit in West Africa, it is not out of place to say that the efficient adoption of coconut palm wood could have a strong impact in boosting sustainable building construction practices in the region. Therefore, it becomes necessary to have a comprehensive understanding of the impediments to the effective utilization of coconut wood in this enormous building sector. Without thorough knowledge of these impediments, the adoption of coconut wood will remain constrained. Most importantly, the greenness traits of the coconut palm wood might be practically lost whilst the vast prospects of efficient utilization of coconut wood to promote sustainable construction will be merely ignored. Thus, it is necessary to investigate these impediments, and provide measures on how to address the impediments, so that, the full utilization of coconut wood can be effectively promoted.

Although this study seeks to use an integrated evaluation approach to analyze the interrelationship among the identified impediments to the use of coconut wood in building construction; there are, at present, various research works that have proposed integrated, innovative and suitable interventions in different aspects of construction. Thus, this aspect represents, without any doubt, a new frontier of the scientific research. This is corroborated by the work of Negro et al. [9], where the researchers adopted an innovative and integrated approach for building rehabilitation using sustainable materials. Their work aimed to provide structural interventions for enhancing the thermal and structural performances of repaired buildings simultaneously. Likewise, an integrated approach was previously adopted by [10] to examine the seismic performance of a multi-span existing masonry arch bridge. These studies further substantiate the use of novel, integrated, and appropriate interventions for various aspects of construction and seek to provide new dimension with respect to research in construction area.

The availability of a few fragmented literatures on the impediments that affect the utilization of coconut wood in building construction makes it absolutely essential to collectively understand these constraints. While the impediments reported in the literature may not be sufficient for a study of this nature, still, the interrelationships among them are yet to be methodically investigated. Proper understanding of the interrelationships among the impediments has a strong influence on the utilization of coconut wood in building construction. For that reason, this study is aimed at conducting a thorough evaluation of the impediments affecting the utilization of coconut wood in West African construction industry and investigate the interrelationships between the impediments. The results of 
this examination are likely expected to provide supportive platform for relevant stakeholders to be equipped with comprehensive understanding of how to use coconut wood as sustainable material in building construction. This could help to provide efficient strategies to fully adopt it in the wider construction sector in the region.

\section{The Impact of Using Non-Traditional Construction Materials on the Environment}

The construction sector around the world is responsible for different environmental issues [11]. It is an energy and resource intensive sector that produces substantial emissions and waste [12]. While steel and concrete are most widely used construction materials, each material has its own advantages and disadvantages based on their costs, properties, and structural performances. However, there is a recently growing concern about the environmental impacts of their production and use. For instance, it is well known that cement is one of the most essential materials required for producing concrete, which is used in the construction of buildings and other physical infrastructure. However, cement production consumes huge amount of energy. Despite many advances in the technological process, the world continues to suffer from the health hazards and other environmental havocs generated by the cement manufacturing companies.

The environment becomes polluted by emissions generated from cement production that worsen the air quality and significantly affects climate change and contributes considerably to global warming. Olivier et al. [13] noted that in 2015, the cement manufacturing industry ranked the third leading global contributor sources of industrial pollution and accounted for nearly eight percent of the entire emissions generated globally. The cement manufacturing industry is renowned for its intense energy and fuel consumption that generate thousand tonnes of greenhouse gases annually [11]. Thus, a radical approach becomes crucial to tackle the issues of global warming and duly mitigate the carbon emissions by almost fifty percent for the next coming forty years [14]. On the other hand, it is not the cement manufacturing industry that predominantly pollutes the environment; the production of construction steel also contributes immensely to environmental pollution.

The adoption of steel, bricks, concrete blocks in construction makes most construction practices generate tremendous amount of greenhouse gases such as $\mathrm{CO}_{2}$. These harmful emissions have a direct impact on the rapid global climate change [15]. Considering the rapid climate change, global warming, and the impact of construction on the environment make the adoption of green building materials in construction an urgent requirement [16]. As pointed out by Salzer et al. [12], the concept of using green building materials in construction has been widely spread and institutionalized in many countries (e.g., Switzerland through SIA 112/1). Thus, advocating for the use of green building materials in West Africa is not merely a regional or an African concern but has considerable and positive effect on the global climate.

Coconut palm wood is a traditional green material that is considered strong, lightweight, and environmentally friendly. The adoption of coconut palm wood in building construction could reduce greenhouse gas emissions and slow down the rapid climatic change [7]. For many centuries, coconut palm wood has been used in some parts of West Africa, as a building material in trusses, rafters, panels, exterior walls, stairs, floorboards, and floor joists. However, the traditional uses of coconut palm wood in building construction have been phased out due to the advent of concrete and steel.

In the past few years, there have been various campaigns advocating for sustainable construction and use of green building materials in construction e.g., coconut wood, bamboo, date palm leaves, grasses, straw, etc. [17-19]. Accordingly, the adoption of coconut palm wood in building residential houses, schools, bridges, scaffolds, has been on the increase in the Philippines, Indonesia, India, Bangladesh, and many countries in the Asia-Pacific region. However, the adoption of coconut palm wood as a green building material in West Africa appears to be ineffective despite the abundance of coconut trees in the region. The adoption of coconut palm wood as a building material in West African countries is relatively lower than in Asia-Pacific region [20]. Thus, this paper is particularly focused on 
investigating the constraints and impediments that hinder the adoption of coconut palm wood as a prospective green building material in the West African construction sector.

\section{Impediments to the Use of Wood as Green Building Material-An Overview}

Globally, the construction industry remains synonymous with practices that are highly energy intensive. These practices lead to outrageous carbon emissions, excessive use of mostly non-renewable materials, and environmental pollution [21]. Thus, the global construction sector is shifting towards sustainable construction practices particularly the use of green materials in building construction [22]. This is considered essential because material efficiency has huge impact on energy consumption as well as carbon emissions [21]. Over the years, there has been remarkable improvement on the adoption of wood in building construction owing to its nature as a renewable construction material that has enormous potentials for promoting sustainable development [23]. It is evident today that in many European countries and Canada for instance, strategic policies have been developed to promote the efficient adoption of wood in building construction [24].

While the adoption of wood in the construction sector has improved slightly in the last decades, it is still not a common construction practice. To date, there are still critical challenges and impediments that persistently affect the wide adoption of wood as a green building material [25]. Previous research works have investigated various impediments to the wide adoption of wood as green building material in the construction sector, but they are mostly fragmented perspectives. Thus, this section aims to highlight some of the existing literature that provide some insight on the impediments influencing the application of wood materials in the context of the construction sector.

To start with, an integrative analysis was adopted by [26] to provide insight on the impediments to the promotion of bamboo as a green building material in China. The authors contributed to the development of literature in the area of bamboo adoption as a green building material. The authors noted that due to stagnation of bamboo material development in China, its wide adoption encountered several impediments. The authors pointed out that 'poor coordination by the government', 'lack of certification mechanisms', 'improper standards \& specifications', 'lack of industry for processing bamboo materials', 'lack of financial incentive plans', and 'lack of code of practice for bamboo application' were the most crucial impediments to the adoption of bamboo as a green building material in China.

Prior to this, various authors had emphasized the impediments related to the use of wood in building construction. These explain why the numerous prospects associated with the use of wood in the construction sector have continuously remained largely unexplored. The most notable of these impediments over the years has been the difficulties related to building codes particularly on issues related to seismic strength, fire safety, and the effect of wind and snow loads [25,27-36]. Other impediments include lack of expertise of the manpower in the proficient use of wood in building construction [25,28,29,31,32,37-39]. Likewise, poor training, ineffective collaboration and technology transfer between academia and the industry, lack of information and support for technical works were equally highlighted by various researchers, as being crucial to the adoption of wood in building construction $[31,32,36,37,39,40]$.

While the cost of using wood is considered a strong driver for its wide adoption in construction, ironically, increased costs due to capital outlay, construction and long-term maintenance costs, and risk aversion of the building sector, combined to make the costs advantage into a critical impediment [27-29,41,42]. Considering the significance of costs in the selection of structural material for building construction; the lack of proficient manpower, anxiety over the resale value, costs of insurance and fire protection costs substantially raise the costs of using wood in construction $[31,41,43,44]$.

The culture of the construction industry has been considered a crucial impediment to the wide adoption of wood in building construction. This is largely attributed to the industry's lack of openness, ultra-conservative attitude, fragmentation of the construction sector, high preferences for established practices and stigmatization of wood as a construction material for the poor $[25,28,31,32,34,44]$. 
Most importantly, the shortage of engineered wood products in the markets and delayed delivery of structural elements adversely propel uncertainties about the wide adoption of wood in building construction $[32,39,41,45]$. Other prominent impediments that were reported in the literature are durability and the technical aspect of the wood $[28,31,32,41,43]$. The technical aspect deals mostly with manufacturing or installation errors, shrinkage of the wood, stiffness, humidity, and concerns related to determining the wood's strength to withstand earthquake and wind $[28,31,44]$.

By way of drawing an inference, the impediments to the adoption of wood as a sustainable construction material that were emphasized in the literature are consistent irrespective of the type of wood under consideration. Thus, this study is aimed at conducting a thorough examination of the impediments that affect the adoption of coconut wood as green material for the construction sector. Further, the study aims to examine the integrated relationships between these impediments. The results of the investigation are expected to support the relevant stakeholders in the industry to create a better understanding of the application of coconut wood as a sustainable construction material and establish effective guidelines for using the coconut wood in building construction. With a better understanding of the impediments to the use of coconut wood in building construction, construction organizations as well as the entrepreneurs in the coconut wood business could adjust their business models and use the wood more in the future to construct innovative structures.

\section{Methods}

An integrated evaluation approach is adopted to achieve the main goal of this study. This evaluation approach involves examining the stratified and hierarchical structure as well as categorizing the impediments from driving to driven perspective. The use of the integrated interpretive structural modelling (ISM) and cross-impact matrix multiplication applied to classification (MICMAC) techniques by researchers in the area of construction has been gaining ground in recent years. Quite a number of researchers in the field of construction [26,46-54] have used the interpretive structural modelling (ISM) and cross-impact matrix multiplication applied to classification (MICMAC) techniques to examine the hierarchical structure between the impediments to a given system or process. Also, the techniques have been used to transform the impediments into clearly visible, easy to understand and quickly interpretable models, based on direct and indirect relationships among the impediments of a system. The researchers used the techniques to also enhance the model significantly by improving the sensitivity of the interrelationships between the impediments, so that if there are any concealed interrelationships of somewhat low weightage, they can be considered, and their impacts can be modelled as well.

The interpretive structural modeling (ISM) and cross-impact matrix multiplication applied to classification (MICMAC) techniques were adopted to examine the hierarchical structure between the impediments to the use of coconut palm wood as a sustainable building material. This is essential because it is mostly believed that the stakeholders for promoting the use of coconut palm wood face difficulties in dealing with the complicated nature of the impediments to the wide use of the coconut wood in building construction. This complexity is due to the presence of many impediments as well as the complicated interactions among these impediments. Not that alone, the presence of directly or indirectly related impediments complicates the issues at hand, which may or may not be expressed in an unambiguous manner [55]. Thus, it becomes quite hard to handle such problems in which the structure is not clearly defined. Therefore, it requires the adoption of the ISM and MICMAC techniques, which will help in identifying a structure within the set of the identified impediments. Using these techniques, a structural model can be developed for the impediments on the basis of their direct and indirect relationships [56]. Most importantly, the direct and indirect relationships between the impediments explain the difficulties to the adoption of the coconut wood far more precisely than the individual impediments taken into isolation. Consequently, the ISM and MICMAC techniques develop insights into collective understandings of these inter-relationships [57]. 
Among the notable advantages of using the ISM and MICMAC techniques in this study is that the adoption of these techniques provides a more vigorous modeling of the information obtained from the experts and provides a closer and easier way to understand and appreciate the resultant information. The improvement and impact that these techniques have on the structural analysis is highly remarkable [55]. Also, these techniques permit the experts to evaluate the influence among the impediments by linguistic terms. This makes it quite easy for the experts to reach consensus on their opinions because the linguistic labels can be defined in line with experts' preferences [56]. While these advantages bring about richer and interpretable results, which make it easier, faster, and more robust to identify the crucial impediments [57], the adoption of these techniques permits policy analysis by assisting the policy makers in determining key areas for policy action. This will provide advantages or leverage in pursuing pre-determined goals [55]. The sections that follow present the methods adopted for achieving the aim of this study.

\subsection{Determining the Impediments}

To start with, content analysis is used to determine some of the impediments that affect the utilization of coconut palm wood in building construction. The rationale for adopting this approach is that content analysis has over the years been proved to be a valuable technique for obtaining and examining data in order to identify research problems from various related literatures. However, due to the paucity of literature in the application of coconut palm wood as a sustainable building material, the number of impediments obtained from the content analysis was quite insufficient for a study of this magnitude. Thus, it became apparent and necessary to supplement the data collection process by considering opinions of experts related to the area of the study.

Only experts experienced on the subject were contacted for the study. The expert-based survey involved one hundred and twenty professionals across the region. As pointed out by [58-60], an expert-based survey with such number of participants can be regarded as sufficient, especially where judgmental sampling is adopted. The adoption of the judgmental sampling becomes necessary considering the level of experience required from the participants to enhance the reliability and validity of the findings. Most importantly, the adoption of this sampling technique made it easy for the research team to remove experts who did not meet the requirements of the survey.

Thus, the list of impediments obtained from the content analysis was presented to the experts during the survey, and the experts were requested to examine the impediments on the list and include other impediments that were not captured in the content analysis. Accordingly, a comprehensive list of thirty-seven impediments that affect the adoption of coconut palm wood in West African region was generated.

The list was formulated based on series of discussions and correspondences with notable experts from the African Timber Organization (ATO), African Forestry and Wildlife Commission (AFWC), West African governmental institutions related to forestry and construction. Other prominent Experts that participated in the study are academics and research communities in the areas of sustainable building materials and construction. These participants are from some of the reputable universities in the region. Most importantly, the list was more consolidated with the inclusion of local construction practitioners with experience in using timber for building construction. Table 1 provides an overview into the composition of the experts that participated in the survey. 
Table 1. Respondents' composition for the data collection process.

\begin{tabular}{ccccc}
\hline \multirow{2}{*}{ Participants } & \multicolumn{2}{c}{ Expert-Based Survey } & \multicolumn{2}{c}{ Semi-Structured Interview } \\
\cline { 2 - 5 } & Number & Percentage & Number & Percentage \\
\hline $\begin{array}{c}\text { Governmental officials } \\
\text { Senior officers at ATO \& AFWC }\end{array}$ & 15 & 13 & 5 & 14 \\
$\begin{array}{c}\text { University Professors \& } \\
\text { Post-doctoral researchers }\end{array}$ & 35 & 6 & 4 & 11 \\
Managers of timber processing & 18 & 15 & 7 & 20 \\
$\quad \begin{array}{c}\text { companies } \\
\text { Timber entrepreneurs }\end{array}$ & 12 & 10 & 5 & 14 \\
Seasoned construction & 33 & 28 & 6 & 17 \\
practitioners & 120 & 100 & 35 & 23 \\
\hline
\end{tabular}

It should be noted that the size of the judgmental sample for this research mostly represents the views of experts from Nigeria, Ghana, Gambia, Liberia, and Sierra Leone. This is to ensure that the communication is effective since respondents from all these countries have English as their official language. However, the impediments identified in the survey are not exclusive to the reality in these five countries; the findings may well be applicable to all other countries in the West African region. This is because countries in the region have homogeneous socio-cultural background, tropical rain forests, construction techniques, and building materials for construction.

The next stage of the data collection process involved an in-depth interview discussion with some of the experts that participated in the earlier survey. This was necessary to gather more consolidated and extensive views of the experts on the impediments to the adoption of coconut palm wood for building construction. The interview was conducted online using the ZOOM cloud platform. In the introductory email sent to the experts, five different timeframes for the meeting were provided to the experts and requested to select the most convenient slot for each expert. Thus, the meeting was held in five batches within two weeks. Only fifty experts replied and invitation links to the interview (meeting) was emailed to them accordingly. Eventually, thirty-five experts were able to participate in the meeting, which is a good response rate. The composition and profiles of the participants are provided in Table 1, and their overall proficiencies significantly enhance the validity to the findings of this study. The participants were presented with the comprehensive list of impediments generated during the expert-based survey and requested to assess how significant does each impediment affect the utilization of coconut palm wood as sustainable building material. The participants were then presented with the following items/tasks on the meeting agenda to ensure effective assessments of the impediments that will enhance the validity of the outcomes of their assessments:

- Ascertain the relevancy of each impediment presented on the list

- Identify and include other significant impediments that were not captured on the list, and to provide justification for the inclusion of such impediment.

- Determining whether the impediments are appropriately expressed in a concise manner. If not, how best to improve?

- Identifying homogeneous impediments and suggesting those to be merged

- Determine whether the impediment significantly affect the adoption of coconut palm wood as building material in the construction sector. If yes, justification should be provided

The authors thereafter analyzed the responses obtained from the participants. Ultimately, a comprehensive list of thirteen crucial impediments that significantly affect the adoption of coconut palm wood as building material in the West African construction sector is produced (Table 2). 
Table 2. Impediments to the adoption of coconut palm wood in West African Building Sector.

\begin{tabular}{cc}
\hline Impediment ID & Description of the Impediments \\
\hline I1 & High costs of processing coconut palm wood \\
I2 & Ineffective incentive scheme \\
I3 & Lack of code of conduct \& enforcement \\
I4 & Lack of intensive programs for research \& development \\
I5 & Lack of processing plants \& techniques \\
I6 & Lack of quality management system \\
I7 & Lack of standards \& specifications \\
I8 & Lack of technology transfer system \\
I9 & Low market demand for coconut palm wood in the construction sector \\
I10 & Perceived low social status for users of coconut palm wood in buildings \\
I11 & Poor knowledge of utilizing coconut palm wood in building construction \\
I13 & Poor regulatory control \\
\hline
\end{tabular}

\subsection{The Integrated Evaluation Approach}

The integrated evaluation approach was used to analyze the interrelationship among the identified impediments by setting up the hierarchy structure between the impediments and then categorizing them from a driving perspective to driven perspective. The hierarchy structure was set up using the interpretive structural modeling technique to describe and simplify the intricate correlation between variables. As corroborated by [61], this technique has been used generally for examining interrelationships among various variables in a complex system. Although the weighted score and mean value techniques could be typically used to examine this kind of interrelationships, however, they do not give an accurate and deep understanding of the complex interrelationship between the impediments under study. Moreover, the need to obtain data from large sample of questionnaire surveys makes the use of the weighted score and mean value techniques quite daunting $[62,63]$. Considering the few number of specialists with sheer wealth of expertise in using coconut palm wood as a building material, the authors opted for the reliable interpretive structural modeling technique. This is considered logical as the authors prioritize the quality over quantity of the responses obtained from the expert-based survey. This view was also buttressed by Ravi and Shankar [64] as they pointed out that minimum of two experienced experts are sufficient to apply the interpretive structural modeling technique in analyzing the hierarchy structure among the impediments.

On the other hand, the categorization of the impediments was done from a driving context to a driven context by making use of the cross-impact matrix multiplication applied to classification (MICMAC) technique. This technique was derived from "Matrice d' Impacts Croises Multiplication Appliqué au Classement". Further, the impediments were grouped according to the magnitude of their driving intensity as well dependence intensity. Thus, categorizing the impediments into two distinct groups (driving power and dependence or driven power) provided a clear profile about the complex interrelationship among the impediments [61]. Figure 1 presents the main steps involved in the integrated evaluation approach using the interpretive structural modeling and cross-impact matrix multiplication applied to classification techniques. It should be noted here that the proposed procedure presented in Figure 1 may be generalized for evaluating any new construction material. Moreover, the combined use of the content analysis, expert-based survey, in-depth semi-structured interview, the interpretive structural modelling (ISM) technique and cross-impact matrix multiplication applied to classification (MICMAC) technique can as well be applied in other areas of construction research to determine impediments and analyze the interrelationship among the identified impediments by setting up the hierarchy structure between the impediments and classifying them from a driving perspective to driven perspective. 


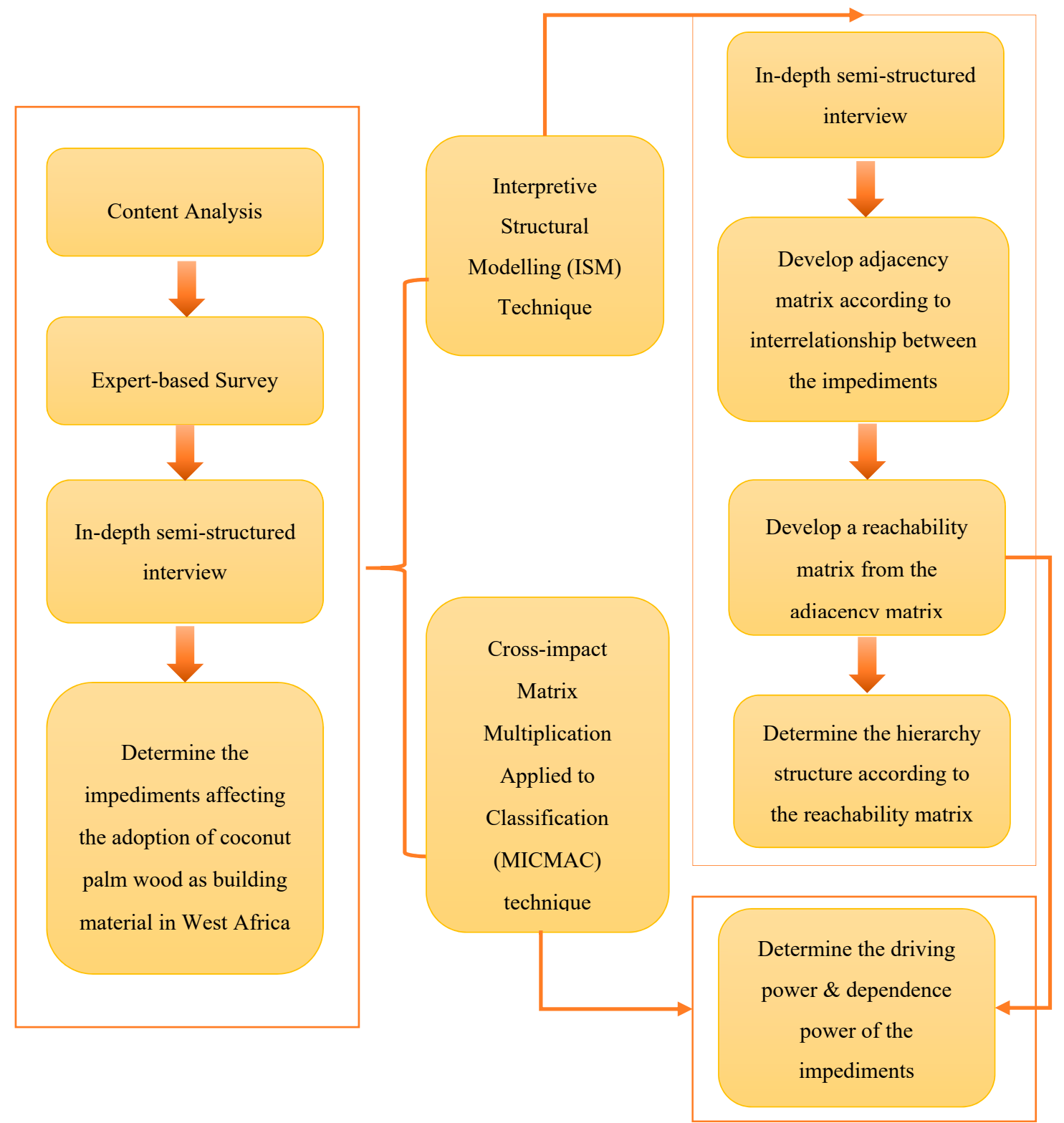

Figure 1. Procedure for conducting the integrated evaluation approach using ISM and MIMAC techniques.

\section{The Impediments to the Use of Coconut Palm Wood as a Sustainable Building Material}

Despite the fact that coconut palm wood is a green and environment friendly building material, its utilization in the building sector in West Africa has remained very low and ineffective. While this study has made strong attempt to promote the material's application, this section presents and describes the major impediments to the effective adoption of coconut palm wood as a green building material.

\subsection{High Costs of Processing Coconut Palm Wood}

The high costs involved in processing raw coconut palm wood remains one of the crucial impediments to its application in building construction. The wood is processed manually, which involves cutting, transporting, processing, and constructing. Unlike bamboo, coconut palm wood does not enjoy a competitive cost advantage as the coconut tree takes about five to six years to grow, thus making its adoption largely constrained. As pointed out by one of the professors during the interview, the cost of processing coconut palm wood is usually five times greater than that of the 
unprocessed coconut wood. Thus, building developers and owners resort to using cheaper alternatives in the markets. Therefore, high processing costs becomes a major impediment to the effective adoption of the coconut palm wood as a green building material in West Africa.

\subsection{Ineffective Incentive Scheme}

The government being the major player and client in the construction sector may consider introducing economic incentive schemes like tax rebates and subsidies in order to motivate and inspire entrepreneurship in the coconut palm wood market. More importantly, the government in each member state in the region may consider making the requirements for benefiting from such benefits flexible and supportive so as not to scare off existing and potential entrepreneurs and all relevant stakeholders in the coconut wood business. One of the timber entrepreneurs noted that at present, most of the economic incentive schemes in the region are fraught with stringent requirements imposed by the governments, very low rates for the tax rebates, and unnecessary long payback period for subsidies. Thus, the incentive schemes are a sham and outrightly ineffective.

\subsection{Lack of Code of Conduct and Enforcement}

Code of conduct and enforcement are essential measures for restricting unethical behaviour in the market, and punitive actions to be taken against market practice violations. The significance of these codes cannot be simply overemphasized. A participant from the African Timber Organization (ATO) affirmed that it will be hard, without these codes, to provide smooth functioning of the market for coconut wood. At present, the continental body responsible for regulating the timber industry in the region does not have a comprehensive code of practice for coconut palm wood application. Not that alone, the institution does not have the system to protect the quality of coconut palm wood being produced. Ultimately, these impediments affect the application of coconut palm wood in building construction.

\subsection{Lack of Intensive Programs for Research and Development}

The shortfall in rigorous systems for research and development is one of the major impediments to the enhanced mass production of coconut palm wood. Initiating mission-oriented research projects on the scientific processes and machinery for production of coconut palm wood will seek to enhance the overall efficiency in the production process. Consequently, quality of the wood products will be enhanced, the production costs will be considerably decreased, and the scope of the coconut wood utilization could be extended. In this regard, the research communities should come up with variety of coconut wood products that would meet the requirements of their target construction market. As noted by one of the managers of timber processing companies, in order to develop complex coconut wood products that would meet the demands and needs of the customers, it is essential to address the problems of funding for research and development, which is quite insufficient. In line with this assertion, one of the local construction practitioners argued that there is dearth of business entrepreneurs in the coconut wood markets, which further complicates the problems.

\subsection{Lack of Processing Industry}

The lack of large-scale commercialized processing industry for coconut wood drives the production costs upwards. At present, there is no major industry for processing the wood in the West Africa. This adversely leads to poor quality of the product, high cost of production, longer construction time and high volume of construction wastes. This lacuna created, widely affects the application of coconut palm wood as a green building material in West Africa. 


\subsection{Lack of Quality Management System}

The lack of robust quality management systems hampers the utilization of coconut palm wood as a green building material. As one of the participants from the African Timber Organization pointed out, there are no quality management systems in the region to certify whether the coconut palm wood being produced meets the prescribed quality requirements or not. This significantly scares off housing developers and construction practitioners from selecting the coconut wood as a green building material. One of the post-doctoral researchers in the interview emphasized on the need to promote wide usage of coconut wood as green building material and called on African Timber Organization and all other relevant agencies to consider listing coconut palm wood in the sustainable building standards implemented in West Africa.

\subsection{Lack of Standards and Specifications}

The lack of standards and specifications affect the wide usage of coconut palm wood as green building material in the region. Developing established standards and specifications will seek to protect the quality of the wood and promote its wide usage in the construction sector. As pointed out by one of the most resourceful construction practitioners during the interview, the lack of standards and specifications makes the building project owners to lose confidence in choosing coconut palm wood as a green building material for their building projects. Another participant from the construction sector pointed out that the lack of standards and specifications for coconut wood makes it difficult to consider using the wood in the design and construction phases. Conversely, bamboo wood is enjoying wide usage in many parts of the world due to the establishment of standards and specifications. Thus, coconut palm wood should not be an exception in order to promote its usage in large scale.

\subsection{Lack of Technology Transfer System}

The establishment of effective technology transfer system seeks to enhance economic development by adopting innovative technologies that involves conveying the technical knowledge from its point of origin to a broader distribution across many users. The lack of technology transfer system denies the business entrepreneurs the chance of benefiting from the technologies produced by the researchers on the application of coconut wood. This could help the entrepreneurs to avoid conducting similar research work. Thus, establishing effective collaborative platform between the research communities and the entrepreneurs could significantly promote the transfer of technology between the two major stakeholders. Ultimately, this will help to promote the usage of coconut palm wood as a green building material.

\subsection{Low Market Demand for Coconut Palm Wood in the Construction Sector}

Generally, there is an apparent low demand for coconut palm wood in the construction sector in Africa. This might be connected to the limited number of coconut wood users/customers in the construction market. There is low awareness on the benefits of using coconut wood as a green building material among building developers and project owners. In contrast, building designers and construction experts hardly recommend coconut wood as a sustainable material for building construction due to their poor understanding of the wood. Thus, it is obvious that low awareness and poor marketing strategies on promoting the use of coconut wood in building construction combine together to hinder the market development for the product, thereby driving a low demand.

\subsection{Perceived Low Social Status for Users of Coconut Palm Wood in Buildings}

In Africa, there is a customary perception that wood materials are predominantly used in providing shelter for local communities where the inhabitants are mostly impoverished. The wood materials are not well processed. The quality and durability of the wood is poor and eventually the price becomes so cheap and easily affordable for the poor local residents. This perceived low social status makes the 
affluent members of the society to detest living in wooden houses, as they do not want to be perceived as being poor. These days, even the poor residents in the communities are not willing to live in wooden houses or construct wooden houses due to this socio-economic stigma. Thus, this long-age customary bias and low awareness about the wood propel the customers to discard coconut palm wood as green building material.

\subsection{Poor Knowledge of Utilizing Coconut Palm Wood in Building Construction}

The poor knowledge of utilizing coconut palm wood in building construction could be attributed to the fragmented nature of the knowledge of its adoption as a green building material. As pointed out by some of the university professors during the interview, there is lack of structured technique that would provide guide to the developmental stages of the coconut wood structures. This adversely affects the customers' choice of coconut palm wood as a sustainable material for construction. Thus, the poor knowledge on the part of the general public in the region, about the nature and usage of coconut palm wood, remains a serious impediment to its adoption in building construction. While the market demand for coconut palm wood in the region is very low, there is dearth of training programs for the relevant construction practitioners. This makes very low proportion of the construction workforce that specialize in coconut wood construction. The lack of capacity development programmes for the workforce on using coconut wood in construction hinders the nurturing of talents and consequently affects the adoption of the wood in building construction.

\subsection{Poor Regulatory Control}

There is clear lack of coordination in the region among the major policy makers regarding the full utilization of coconut wood in the building sector. While some governmental agencies have issued policy papers on developmental plans for the coconut wood industry, other relevant policy makers do not have such clear and comprehensive plans. The African Timber Organization and governmental agencies in each West African state are yet to publish a standard industry development plan for coconut wood and other woods like bamboo. The major policy makers have vital role to play in advocating the use of coconut palm wood particularly during the early stages of the awareness campaigns. It was noted during the interview that the awareness programmes on the application of the wood in building construction are not adequate and are largely ineffective. It will be difficult to establish specifications on the use of coconut wood with ineffective awareness campaigns, and this could affect its wide application in the building sector of the region.

\subsection{Reluctance in Coconut Palm Wood Entrepreneurship}

Reluctance of entrepreneurs in engaging actively in the coconut wood business brings about poor market drive among the players and entrepreneurs will not be interested in the high-tech inventions. The reluctance on the part of the entrepreneurs adversely affects cost of production and efficiency of the production processes, which eventually would hinder the adoption of the wood in the construction sector. As pointed out by one of the timber entrepreneurs in the region, there are few business enterprises that are active in the coconut wood market and this constrains the adoption of the coconut wood in building construction in the region.

\section{Integrated Evaluation of the Impediments}

This section presents the integrated evaluation of the impediments to the utilization of coconut palm wood in building construction. The evaluation approach involved analyzing the stratified and hierarchical structure between the impediments by making use of the interpretive structural modeling technique and categorizing the impediments from driving context to driven context using the cross-impact matrix multiplication applied to classification technique. 


\subsection{Establishment of the Hierarchy Structure among the Impediments}

To start with, the interpretive structural modeling technique was utilized to create a hierarchy structure among the thirteen established impediments that hinder the adoption of coconut palm wood in building construction in West Africa. The established hierarchical structure is considered valuable in interpreting the complex relationship between the impediments.

\subsubsection{Development of the Adjacency Matrix}

The adjacency matrix developed under the interpretive structural modeling technique is widely used to describe the contextual interrelationship among the determined impediments. To do this, expert judgments are essential to create the contextual interrelationships among the impediments. To comprehend the interactive interrelationship among the impediments, a contextual interrelationship of "direct impact" was used to suggest that one impediment has direct impact on another impediment. For instance, impediment $X$ affects impediment $Y$, and impediment $Y$ affects $Z$. Accordingly, the relationship between impediment $X$ and $Y$ is a direct impact while the relationship between impediment $X$ and impediment $Z$ is an indirect impact. On the contrary, the concept of "direct impact" should be closely examined in some cases. For instance, impediment $X$ may have direct impact on impediment $Y$, but impediment $Y$ may not have a direct impact on impediment $X$.

Based on the concepts of the interpretive structural modeling technique, the qualitative interpretation of the relationship among the impediments could be easily converted into an adjacency matrix. Thus, the interpretation of the interrelationship among any two impediments is indicated by one or zero in the adjacency matrix. The criteria for describing this interpretation are provided below.

- If impediment $X$ directly affects impediment $Y, 1$ will be assigned in the matrix. If not, then, 0 will be the assigned score in the $(X, Y)$ entry.

- If impediment $Y$ directly affects impediment $X, 1$ will be assigned in the matrix. If not, then, 0 will be the assigned score in the $(\mathrm{Y}, \mathrm{X})$ entry.

- If impediment $X$ directly affects impediment $Y$, and impediment $Y$ concurrently affects impediment $X$ directly, a score of 1 will be assigned in the $(X, Y)$ and $(Y, X)$ entry.

In order to evaluate the contextual relationship among the thirteen impediments determined, the thirty-five participants carried out pairwise evaluation on the impediments by providing a response to the question "do you think impediment $X$ has direct impact on impediment $Y$ ?". Since various specialists may assess the relationship in a different way, the final outcomes from the participants' judgment were in accordance with the concept of "the minority gives way to the majority". Accordingly, the interrelationships among the thirteen impediments were formed in the adjacency matrix presented in Table 3.

Table 3. The adjacency matrix among the entire impediments.

\begin{tabular}{cccccccccccccc}
\hline & I13 & I12 & I11 & I10 & I9 & I8 & I7 & I6 & I5 & I4 & I3 & I2 & I1 \\
\hline I1 & 0 & 0 & 0 & 0 & 1 & 0 & 0 & 0 & 0 & 0 & 0 & 0 & 1 \\
I2 & 1 & 0 & 0 & 0 & 0 & 0 & 0 & 0 & 0 & 0 & 0 & 1 & 0 \\
I3 & 1 & 0 & 0 & 0 & 0 & 0 & 0 & 0 & 0 & 0 & 1 & 0 & 0 \\
I4 & 0 & 0 & 0 & 0 & 1 & 0 & 0 & 0 & 0 & 1 & 0 & 0 & 0 \\
I5 & 0 & 0 & 0 & 1 & 0 & 0 & 0 & 0 & 1 & 0 & 0 & 0 & 1 \\
I6 & 0 & 0 & 0 & 0 & 0 & 0 & 1 & 1 & 0 & 0 & 1 & 0 & 0 \\
I7 & 0 & 0 & 0 & 0 & 0 & 0 & 1 & 0 & 0 & 0 & 1 & 0 & 0 \\
I8 & 0 & 0 & 0 & 0 & 0 & 1 & 0 & 0 & 0 & 0 & 0 & 0 & 0 \\
I9 & 0 & 0 & 0 & 0 & 1 & 0 & 0 & 0 & 0 & 0 & 0 & 0 & 0 \\
I10 & 1 & 0 & 1 & 1 & 1 & 0 & 0 & 0 & 0 & 0 & 0 & 0 & 0 \\
I11 & 0 & 0 & 1 & 1 & 1 & 0 & 0 & 0 & 0 & 0 & 0 & 0 & 0 \\
I12 & 1 & 1 & 1 & 0 & 0 & 1 & 1 & 1 & 0 & 0 & 1 & 1 & 0 \\
I13 & 1 & 0 & 1 & 0 & 0 & 0 & 0 & 0 & 0 & 1 & 0 & 0 & 1 \\
\hline
\end{tabular}




\subsubsection{Development of the Reachability Matrix}

From the adjacency matrix presented in Table 3, it is mainly the direct interactions between the thirteen impediments that were established and not indirect interactions between the impediments. Thus, it became paramount to come up with the reachability matrix to establish the direct and indirect interactions between the impediments in a matrix. Based on the direct relationships established in the adjacency matrix, the reachability matrix was developed using power iteration analyses. The reachability matrix is presented in Table 4 . From the table, a score of one signifies that the two impediments under pairwise comparison have either a direct interrelationship or an indirect interrelationship.

Table 4. The reachability matrix among the entire impediments.

\begin{tabular}{cccccccccccccccc}
\hline & I13 & I12 & I11 & I10 & I9 & I8 & I7 & I6 & I5 & I4 & I3 & I2 & I1 & $\begin{array}{c}\text { Driving } \\
\text { Intensity }\end{array}$ & Rank \\
\hline I1 & 0 & 0 & 0 & 0 & 1 & 0 & 0 & 0 & 0 & 0 & 0 & 0 & 1 & 2 & 6 \\
I2 & 1 & 0 & 1 & 1 & 1 & 0 & 0 & 0 & 0 & 1 & 0 & 1 & 1 & 7 & 4 \\
I3 & 1 & 0 & 1 & 1 & 1 & 0 & 0 & 0 & 0 & 1 & 1 & 0 & 1 & 7 & 4 \\
I4 & 0 & 0 & 0 & 0 & 1 & 0 & 0 & 0 & 0 & 1 & 0 & 0 & 0 & 2 & 6 \\
I5 & 1 & 0 & 1 & 1 & 1 & 0 & 0 & 0 & 1 & 1 & 0 & 0 & 1 & 7 & 4 \\
I6 & 1 & 0 & 1 & 1 & 1 & 0 & 1 & 1 & 0 & 1 & 1 & 0 & 1 & 9 & 2 \\
I7 & 1 & 0 & 1 & 1 & 1 & 0 & 1 & 0 & 0 & 1 & 1 & 0 & 1 & 8 & 3 \\
I8 & 0 & 0 & 0 & 0 & 0 & 1 & 0 & 0 & 0 & 0 & 0 & 0 & 0 & 1 & 7 \\
I9 & 1 & 0 & 0 & 0 & 1 & 0 & 0 & 0 & 0 & 0 & 0 & 0 & 0 & 2 & 6 \\
I10 & 1 & 0 & 1 & 1 & 1 & 0 & 0 & 0 & 0 & 1 & 0 & 0 & 1 & 6 & 5 \\
I11 & 1 & 0 & 1 & 1 & 1 & 0 & 0 & 0 & 0 & 1 & 0 & 0 & 1 & 6 & 5 \\
I12 & 1 & 1 & 1 & 1 & 1 & 1 & 1 & 1 & 0 & 1 & 1 & 1 & 1 & 12 & 1 \\
I13 & 1 & 0 & 1 & 1 & 1 & 0 & 0 & 0 & 0 & 1 & 0 & 0 & 1 & 6 & 5 \\
\hline Dependence & 10 & 1 & 9 & 9 & 12 & 2 & 3 & 2 & 1 & 10 & 4 & 2 & 10 & $75 / 75$ & \\
Intensity & & & & & & & & & & & & & & & \\
\hline Rank & 2 & 7 & 3 & 3 & 1 & 6 & 5 & 6 & 7 & 2 & 4 & 6 & 2 & & \\
\hline
\end{tabular}

\subsubsection{Development of the Hierarchical Structure}

Developing the hierarchical structure for the required the identification of level partitions for each impediment. The outcomes of the level partitions for the entire impediments under study are provided in Tables 5-11. Further, the number of level partition as well as the intersection, antecedent, and reachability sets, are clearly provided in each table of level partition. The reachability set for each impediment involved the impediment itself as well as the other impediments it reached. The impediments reached are known as reachable impediments. From the reachability matrix presented in Table 4, the reachable impediments for each impediment are those impediments having an assigned score of 1 in the row related to the particular impediment in the table e.g., the reachable impediments for I1 (high costs of processing coconut palm wood) row-wise are I9 and I1. Similarly, the reachable impediments for I2 (ineffective incentive scheme) are I13, I11, I10, I9, I4, I2 and I1.

Similarly, the antecedent set for each impediment involves the impediment itself as well as the other impediments it reached. From the reachability matrix presented in Table 4, the reachable impediments for each impediment are those impediments having an assigned score of 1 in the column related to the particular impediment in the table e.g., the reachable impediments for impediments \#3 (lack of code of conduct \& enforcement) column-wise are I3, I6, I7, and I12. Table 4 further shows the intersection set for each impediment. The intersection set for each impediment involves the impediments that are common to both its reachability set and antecedent set e.g., the intersection set for impediment \#13 (reluctance in coconut palm wood entrepreneurship) are I9, I10, I11, and I13. 
Table 5. Level 1 partition of reachability matrix.

\begin{tabular}{|c|c|c|c|c|}
\hline Impediment & Reachability Set & Antecedent Set & Intersection Set & Level \\
\hline 1 & 1,9 & $1,2,3,5,6,7,10,11,12,13$ & 1 & \\
\hline 2 & $1,2,4,9,10,11,13$ & 2,12 & 2 & \\
\hline 3 & $1,3,4,9,10,11,13$ & $3,6,7,12$ & 3 & \\
\hline 4 & 4,9 & $2,3,4,5,6,7,10,11,12,13$ & 4 & \\
\hline 5 & $1,4,5,9,10,11,13$ & 5 & 5 & \\
\hline 6 & $1,3,4,6,7,9,10,11,13$ & 6,12 & 6 & \\
\hline 7 & $1,3,4,7,9,10,11,13$ & $6,7,12$ & 7 & \\
\hline 8 & 8 & 8,12 & 8 & L1 \\
\hline 9 & 9,13 & $1,2,3,4,5,6,7,9,10,11,12,13$ & 9,13 & \\
\hline 10 & $1,4,9,10,11,13$ & $2,3,5,6,7,10,11,12,13$ & $10,11,13$ & \\
\hline 11 & $1,4,9,10,11,13$ & $2,3,5,6,7,10,11,12,13$ & $10,11,13$ & \\
\hline 12 & $1,2,3,4,6,7,8,9,10,11,12,13$ & 12 & 12 & \\
\hline 13 & $1,4,9,10,11,13$ & $2,3,5,6,7,9,10,11,12,13$ & $9,10,11,13$ & \\
\hline
\end{tabular}

Table 6. Level 2 partition of reachability matrix.

\begin{tabular}{|c|c|c|c|c|}
\hline Impediment & Reachability Set & Antecedent Set & Intersection Set & Level \\
\hline 1 & 1,9 & $1,2,3,5,6,7,10,11,12,13$ & 1 & \\
\hline 2 & $1,2,4,9,10,11,13$ & 2,12 & 2 & \\
\hline 3 & $1,3,4,9,10,11,13$ & $3,6,7,12$ & 3 & \\
\hline 4 & 4,9 & $2,3,4,5,6,7,10,11,12,13$ & 4 & \\
\hline 5 & $1,4,5,9,10,11,13$ & 5 & 5 & \\
\hline 6 & $1,3,4,6,7,9,10,11,13$ & 6,12 & 6 & \\
\hline 7 & $1,3,4,7,9,10,11,13$ & $6,7,12$ & 7 & \\
\hline 9 & 9,13 & $1,2,3,4,5,6,7,9,10,11,12,13$ & 9,13 & L2 \\
\hline 10 & $1,4,9,10,11,13$ & $2,3,5,6,7,10,11,12,13$ & $10,11,13$ & \\
\hline 11 & $1,4,9,10,11,13$ & $2,3,5,6,7,10,11,12,13$ & $10,11,13$ & \\
\hline 12 & $1,2,3,4,6,7,9,10,11,12,13$ & 12 & 12 & \\
\hline 13 & $1,4,9,10,11,13$ & $2,3,5,6,7,9,10,11,12,13$ & $9,10,11,13$ & \\
\hline
\end{tabular}

Table 7. Level 3 partition of reachability matrix.

\begin{tabular}{ccccc}
\hline Impediment & Reachability Set & Antecedent Set & Intersection Set & Level \\
\hline 1 & 1 & $1,2,3,5,6,7,10,11,12,13$ & 1 & L3 \\
2 & $1,2,4,10,11,13$ & 2,12 & 2 & \\
3 & $1,3,4,10,11,13$ & $3,6,7,12$ & 3 & L3 \\
4 & 4 & $2,3,4,5,6,7,10,11,12,13$ & 5 & \\
5 & $1,4,5,10,11,13$ & 5 & 6 & 7 \\
6 & $1,3,4,6,7,10,11,13$ & 6,12 & $10,11,13$ \\
7 & $1,3,4,7,10,11,13$ & $6,7,12$ & $10,11,13$ \\
10 & $1,4,10,11,13$ & $2,3,5,6,7,10,11,12,13$ & 12 \\
11 & $1,4,10,11,13$ & $2,3,5,6,7,10,11,12,13$ & \\
12 & $1,2,3,4,6,7,10,11,12,13$ & 12 & $10,11,13$ \\
\hline
\end{tabular}

The next stage in the development of the hierarchical structure involves identifying the level partition among the impediments. This is done by identifying those impediments to which their reachability set is the same as their intersection set. From Table 5 for example, I8 (Lack of technology transfer system) has the same reachability set as well as intersection set. Thus, this impediment (I8) was partitioned as a Level 1 impediment. Based on the concepts of the interpretive structural modeling technique, the Level 1 impediment (I8) would be removed from Table 5 in subsequent analysis. The same method was used to determine the rest impediments at Level 2, 3, 4, 5, 6, and 7 as presented in Tables 6-11. The outcomes of the level partitioning between the impediments are presented in Table 12. 
Thus, the interpretive structural modeling-based hierarchy structure among the entire impediments (Figure 2) was developed using the information provided in Table 12.

Table 8. Level 4 partition of reachability matrix.

\begin{tabular}{ccccc}
\hline Impediment & Reachability Set & Antecedent Set & Intersection Set & Level \\
\hline 2 & $2,10,11,13$ & 2,12 & 2 & \\
3 & $3,10,11,13$ & $3,6,7,12$ & 3 & \\
5 & $5,10,11,13$ & 5 & 5 & \\
6 & $3,6,7,10,11,13$ & 6,12 & 6 & \\
7 & $3,7,10,11,13$ & $6,7,12$ & 7 & \\
10 & $10,11,13$ & $2,3,5,6,7,10,11,12,13$ & $10,11,13$ & $\mathrm{~L} 4$ \\
11 & $10,11,13$ & $2,3,5,6,7,10,11,12,13$ & $10,11,13$ & $\mathrm{~L} 4$ \\
12 & $2,3,6,7,10,11,12,13$ & 12 & 12 & \\
13 & $10,11,13$ & $2,3,5,6,7,10,11,12,13$ & $10,11,13$ & $\mathrm{~L} 4$ \\
\hline
\end{tabular}

Table 9. Level 5 partition of reachability matrix.

\begin{tabular}{ccccc}
\hline Impediment & Reachability Set & Antecedent Set & Intersection Set & Level \\
\hline 2 & 2 & 2,12 & 2 & L5 \\
3 & 3 & $3,6,7,12$ & 3 & L5 \\
5 & 5 & 5 & 5 & L5 \\
6 & $3,6,7$ & 6,12 & 6 & \\
7 & 3,7 & $6,7,12$ & 7 & \\
12 & $2,3,6,7,12$ & 12 & 12 & \\
\hline
\end{tabular}

Table 10. Level 6 partition of reachability matrix.

\begin{tabular}{ccccc}
\hline Impediment & Reachability Set & Antecedent Set & Intersection Set & Level \\
\hline 6 & 6,7 & 6,12 & 6 & L6 \\
7 & 7 & $6,7,12$ & 7 & L6 \\
12 & $6,7,12$ & 12 & 12 & \\
\hline
\end{tabular}

Table 11. Level 7 partition of reachability matrix.

\begin{tabular}{ccccc}
\hline Impediment & Reachability Set & Antecedent Set & Intersection Set & Level \\
\hline 12 & 12 & 12 & 12 & L7 \\
\hline
\end{tabular}

Table 12. Level partitions for the entire impediments-Summary of results.

\begin{tabular}{ccc}
\hline Partitioning Level & Impediment ID & Impediment Description \\
\hline L1 & I8 & Lack of technology transfer system \\
\hline L2 & I9 & Low market demand for CPW in the construction sector \\
\hline L3 & I1 & High costs of processing CPW \\
& I4 & Lack of intensive programs for research \& development \\
\hline L4 & I10 & Perceived low social status for users of CPW in buildings \\
& I11 & Poor knowledge of utilizing CPW in building construction \\
& I13 & Reluctance in Coconut Palm Wood entrepreneurship \\
\hline L5 & I2 & Ineffective incentive scheme \\
& I3 & Lack of code of conduct \& enforcement \\
I5 & I6 & Lack of processing plants \& techniques \\
\hline L6 & I7 & Lack of standards \& specifications \\
\hline L7 & I12 & Poor regulatory control \\
\hline
\end{tabular}




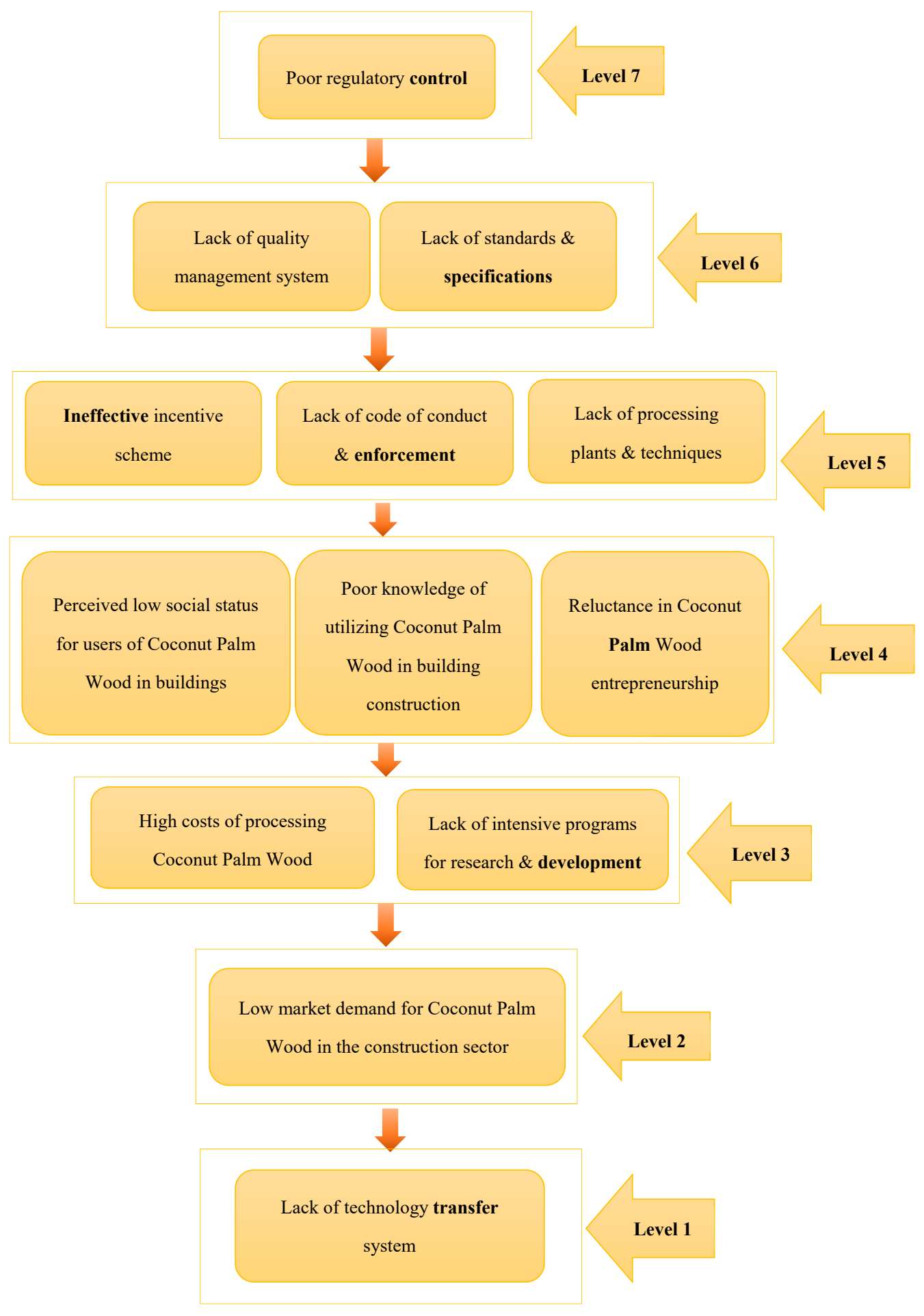

Figure 2. The hierarchical structure of the entire impediments.

It is obvious from Figure 2 and Table 4 that the highest level (L7) and the top-most ranked (1) impediment respectively is the I12, which is "poor regulatory control". Thus, this is the most crucial impediment to the adoption of coconut palm wood in building construction in West Africa. This indicates that the efficacy in overcoming this constraint will greatly have an impact on promoting the adoption of coconut palm wood as a green building material in the region. In contrast, I8 (lack of technology transfer system) became the lowest level (L1) and the least ranked (7) impediment as shown in Figure 2 and Table 4, respectively. This strongly implies that "lack of technology transfer system" is a 
superficial impediment that is influenced by all other impediments. Also, "poor knowledge of utilizing coconut palm wood in building construction" (I11) and "lack of processing plants $\mathcal{E}$ techniques" (I5), which are mid-level impediments, contributed to the perceived low social status for users of coconut palm wood in buildings (I10). Eventually, this resulted to the low market demand for coconut palm wood in the construction sector (I9).

\subsection{Classification of the Impediments}

The impediments were categorized using the cross-impact matrix multiplication applied to classification (MICMAC) technique. This technique was used in accordance with the reachability matrix in Table 4 to examine the driving power as well as the dependence power (driven power) of the impediments. The driving intensity of a particular impediment means the entire impediments it affects. This can be determined by summing up all the assigned scores of the row related to the particular impediment in the reachability matrix (Table 4) e.g., the driving power of I1 is 2 and I 2 is 7 . On the contrary, the dependence intensity of a particular impediment means the entire impediments influencing this particular impediment. This can be determined by summing up all the entry scores of the column related to the particular impediment in the reachability matrix (Table 4) e.g., the dependence intensity I1 is 10 and I2 is 2 . Thus, the driving intensity and dependence intensity for the entire impediments can be determined as shown in Table 4 and summarized and presented in Table 13.

Table 13. Summary of the driving intensity and dependence intensity of the impediments.

\begin{tabular}{cccccccccccccc}
\hline Impediments & I1 & I2 & I3 & I4 & I5 & I6 & I7 & I8 & I9 & I10 & I11 & I12 & I13 \\
\hline Driving Intensity & 2 & 7 & 7 & 2 & 7 & 9 & 8 & 1 & 2 & 6 & 6 & 12 & 6 \\
Dependence Intensity & 10 & 2 & 4 & 10 & 1 & 2 & 3 & 2 & 12 & 9 & 9 & 1 & 10 \\
\hline
\end{tabular}

The information provided in Table 13 is then used to position each impediment in the diagram presented in Figure 3. The impediments in Figure 3 were grouped into four classes namely, driving, linkage, dependent and autonomous impediments. The driving impediments are those impediments that possess high driving intensity and weak dependence intensity i.e., I2, I3, I5, I6, I7, and I12. These impediments have tendency to affect other impediments. In other words, they are crucial to promoting coconut palm wood as a green building material. Thus, these impediments deserve the highest attention in developing policies for advocating the utilization of coconut palm wood in building construction.

The linkage impediments are those impediments that possess high driving intensity as well as high dependence intensity. In other words, they are considered to be sensitive and unstable because anything that affects these impediments will have an immediate impact on other impediments as well as a feedback impact on themselves. It is obvious from Figure 3 that there are no linkage impediments among the identified impediments. However, the dependent impediments include those impediments that possess weak driving intensity and high dependence intensity. From Figure 3, the dependent impediments are I1, I4, I9, I10, I11, I13 and their impact on the adoption of coconut palm wood in building construction essentially depends on other impediments.

This means that if other impediments are controlled, these impediments would be controlled as well. Thus, these impediments are considered not crucial to the application of coconut palm wood in building construction. Autonomous impediments on the other hand, are those impediments possessing weak driving intensity as well as weak dependence intensity. They are comparatively separated from the group they are classified into, within which they have little or no relationship. It could be seen from Figure 3 that only I8 falls into this category. This seems to suggest that relationship between lack of technology transfer system and other impediments is weak. Thus, it could not influence the adoption of coconut palm wood in building construction. 


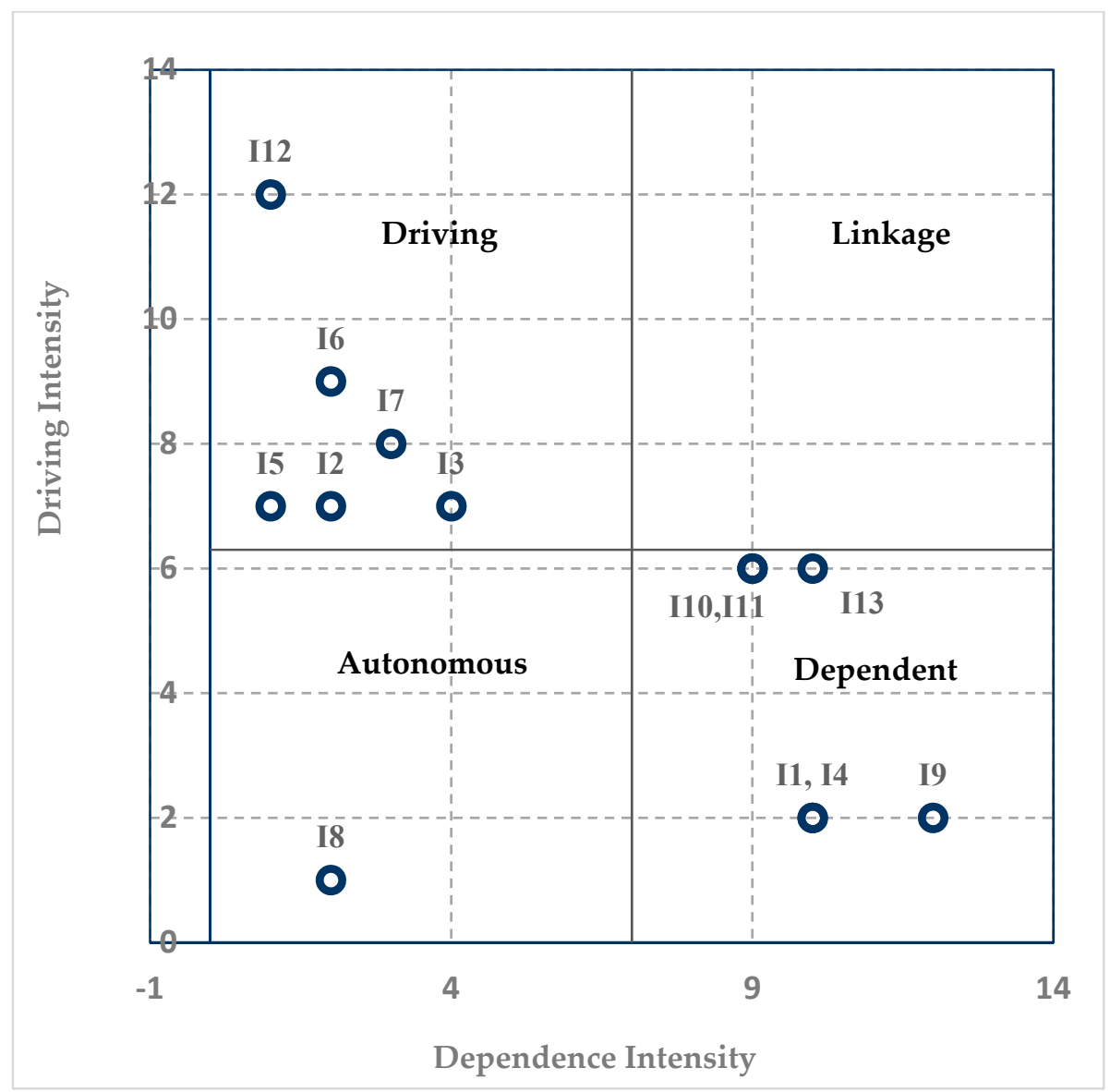

Figure 3. Two-dimensional diagram of the driving intensity and dependence intensity of the impediments.

\section{Discussion}

A closer look at the hierarchical structure of the entire impediments presented in Figure 2 will show that the driving impediments, which includes poor regulatory control (I12), lack of standards \& specifications (I7), lack of quality management system (I6), lack of processing plants \& techniques (I5), lack of code of conduct \& enforcement (I3) and ineffective incentive scheme (I2), occupy the higher levels in the hierarchical structure. Similarly, in the two-dimensional diagram presented in Figure 3, the same driving impediments occupy the upper quadrant for the driving intensity and dependence intensity of the impediments. This certainly indicates that these impediments are the most critical and deserve urgent attention of all relevant policy makers and stakeholders to boost the adoption of coconut palm wood in building construction. While the highest priority should be given to poor regulatory control (I12) in particular, nonetheless, the significance of lack of standards \& specifications (I7), and lack of quality management system (I6), could not be overemphasized. This is quite true because in the construction industry, these impediments play vital roles in the adoption of particular building materials. For coconut palm wood to be widely adopted in the building sector, standards and specifications must be duly developed because these are the drivers that will promote the quality of its application and boost the confidence of its users. Since most coconut wood entrepreneurs and processing plants have little or no influence in establishing standards and specifications, the African Timber Organization, and governments of the member states in the region have a big role to play. The establishment of the standards and specifications for the application of coconut wood has been long overdue. It is highly needed now more than ever, to promote the adoption of coconut palm wood in building construction. 
On the other hand, the lack of processing plants \& techniques (I5) has a considerable driving impact as it will directly influence the perceived low social status for users of coconut palm wood in buildings (I10), which is a crucial obstacle to owners and end-users of residential buildings to accept coconut wood as a building material. While the development of an effective incentive scheme (I2) will seek to promote the participation of businessmen to join the coconut wood industry, the establishment of code of conduct \& enforcement (I3) will help to ensure fair competition among the key players and promote healthy and sustained development of the industry.

The dependent impediments shown in Figure 3 (I1, I4, I9, I10, I11, I13) are inconsequential impediments whose impact on the adoption of coconut palm wood is influenced by the driving impediments discussed earlier. Thus, the performance of these dependent impediments could be mainly improved if the related driving impediments are well addressed. For instance, the performance of "reluctance in coconut palm wood entrepreneurship" (I13), which is dependent impediment, is highly influenced by "poor regulatory control" (I12), which is a driving impediment. Further, if "poor regulatory control" provides strong support to "poor knowledge of utilizing coconut palm wood in building construction" (I11), which is a dependent impediment, then, it is expected that the performance of "perceived low social status for users of coconut palm wood in buildings" (I10) and "low market demand for coconut palm wood in the construction sector" (I9) will be duly enhanced significantly. The only impediment classified as autonomous and shown in Figure 3 is "lack of technology transfer system" (I8). This autonomous impediment is less associated with other impediments; it is comparatively neutral and not influenced by other impediments. Thus, this impediment has weak driving power as well dependence power. As pointed out by Salzer et al. (2016), technology transfer contributes to the development of a particular sector in a direct and effective way. Thus, "lack of technology transfer system" could influence the promotion of coconut palm wood adoption without strong support of other impediments in the system.

\section{Summary}

This section presents suggestions for policymakers and practitioners to adopt effective policies and measures to overcome the impediments identified and to provide a platform for promoting the wide adoption of coconut wood in building construction. The government, being the major policy maker, is expected to provide effective regulatory control and coordination between all relevant stakeholders in the industry particularly on the manufacture and use of coconut wood in building construction. The knowledge about coconut wood adoption can be integrated to provide useful concept and techniques for managing the design, construction and maintenance works that require the use of coconut wood. To the general public, extensive awareness campaigns are required to orient people about the nature and use of the wood in building construction. The government may also consider establishing an industry for processing coconut wood to ensure high production efficiency and reduce the high production costs. While the provision of processing plants and techniques directly influences the perceived low social status for users of coconut wood in buildings, it is this traditional bias that hinders the users from accepting the wood as a green building material. In order to protect the quality of coconut wood adoption, the regulatory authorities are expected to guide the process of establishing appropriate certification systems, standards and specifications, which may likely boost the users' confidence to adopt coconut wood for their construction projects. Thus, the promotion of coconut wood adoption in the construction sector requires monetary incentives and motivations like tax cuts and subsidies to attract entrepreneurs to join the industry. 


\section{Conclusions}

In the construction industry, the adoption of coconut palm wood as a sustainable material for building construction has broad prospects, especially in the context of sustainable construction. While the merits of adopting coconut palm wood in building construction have been outlined in this study, the development of the material in West African region has been quite slow. This could be attributed largely to the numerous encountered impediments, which must be overcome in order to promote the wide adoption of the material in building construction. Thus, this study determined the thirteen most crucial impediments to adoption of the coconut palm wood in building construction. Thereafter, the interpretive structural modelling technique was used to structure the impediments into a hierarchical structure. The MICMAC classification technique was further used to categorize the impediments into different groups (in a two-dimensional diagram) in accordance with their driving or driven intensity.

The outcomes of this study suggest that "poor regulatory control and coordination" is the most crucial impediment to the adoption of coconut palm wood in building construction in West Africa. Not that alone, the study also found out the impediments with strong driving powers for the adoption of coconut palm wood as a green building material. These impediments include lack of standards \& specifications, lack of quality management system, lack of processing plants \& techniques, lack of code of conduct \& enforcement and ineffective incentive scheme. In contrast, the impediments with strong dependencies on other impediments were also determined. This include high costs of processing coconut palm wood, lack of intensive programs for research \& development, low market demand for coconut palm wood in the construction sector, perceived low social status for users of coconut palm wood in buildings, poor knowledge of utilizing coconut palm wood in building construction, and reluctance in coconut palm wood entrepreneurship.

The findings of this paper are expected to provide significant guide to policy and decision makers to develop potent and coherent policies that would stimulate the wide adoption of coconut palm wood as a green building material. Thus, this study promotes the enhancement of sustainable construction practices in West Africa. The formation of the hierarchical structure among the impediments will seek to ensure the provision of vital information required for identifying the crucial areas to be tackled. A proper understanding of these impediments and their associated hierarchical structure would seek to provide guide to construction industry practitioners for their involvement in effectively using the coconut wood in building construction. More importantly, the concerned authorities would be guided accordingly to formulate effective policies, regulations, and standards that will promote the development as well as the wide adoption of coconut palm wood in the construction industry. In essence, if these crucial impediments are properly tackled and controlled, the adoption of coconut palm wood will have a huge potential of stimulating sustainable construction practices in West African construction industry. However, it should be noted that advocating for the use of sustainable materials for building construction in West Africa is beyond the boundaries of the region, it cuts across the continent and has a huge potential effect on African climate as well as the global climate. It is expected that from the findings of this paper, it is possible for all relevant stakeholders to initiate effective strategies for combating the identified impediments in order to realize the full potentials of adopting coconut wood as green building material in the construction sector. Above all, this paper adequately enriches the literature in the area of coconut palm wood adoption as a green building material.

Author Contributions: The following contributions were made by each author: conceptualization, M.S. and Z.A.K.; methodology, M.S.; validation, Z.A.K. and M.S.; formal analysis, Z.A.K.; writing-original draft preparation, Z.A.K. and M.S.; writing—review and editing, Z.A.K. and M.S.; visualization, Z.A.K.; supervision, M.S. and Z.A.K.; project administration, Z.A.K. All authors have read and agreed to the published version of the manuscript.

Funding: This research received no external funding.

Conflicts of Interest: The authors declare no conflict of interest. 


\section{References}

1. Bah, E.M.; Faye, I.; Geh, Z.F. The Housing Sector in Africa: Setting the Scene. In Housing Market Dynamics in Africa; Palgrave Macmillan: London, UK, 2018. [CrossRef]

2. PourRahimian, F.; Goulding, J.; Akintoye, A.; Kolo, S. Review of Motivations, Success Factors, and Barriers to the Adoption of Offsite Manufacturing in Nigeria. Procedia Eng. 2017, 196, 512-519. [CrossRef]

3. Ganiyu, B.O.; Fapohunda, J.A.; Haldenwang, R. Sustainable housing financing model to reduce South Africa housing deficit. Int. J. Hous. Mark. Anal. 2017, 10, 410-430. [CrossRef]

4. Osumanu, I.S.; Aigbavboa, C.O.; Thwala, D.W. Examining the Relationship between Lean Adoption and Housing Finance in Ghana. In AHFE 2018: Advances in Affective and Pleasurable Design; Fukuda, S., Ed.; Springer: Cham, Switzerland, 2019; Volume 774. [CrossRef]

5. Liew, K.M.; Sojobi, A.O.; Zhang, L.W. Green concrete: Prospects and challenges. Constr. Build. Mater. 2017, 156, 1063-1095. [CrossRef]

6. Kulshreshtha, Y.; Mota, N.J.A.; Jagadish, K.S.; Bredenoord, J.; Vardon, P.J.; Loosdrecht, M.C.M.; Jonkersg, H.M. The potential and current status of earthen material for low-cost housing in rural India. Constr. Build. Mater. 2020, 247, 118615. [CrossRef]

7. Rana, M.N.; Das, A.K.; Ashaduzzaman, M. Physical and mechanical properties of coconut palm (Cocos nucifera) stem. Bangladesh J. Sci. Ind. Res. 2015, 50, 39-46. [CrossRef]

8. Asia-Pacific Forestry Commission (APFC). Asia-Pacific Forestry Sector Outlook Study: The Utilization, Processing and Demand for Rubberwood as a Source of Wood Supply; FAO of the United Nations Regional Office for Asia and the Pacific: Bangkok, Thailand, 2000.

9. Negro, E.; Damato, M.; Cardinale, N. Non-invasive Methods for Energy and Seismic Retrofit in Historical Building in Italy. Front. Built Environ. 2019, 5, 1-13. [CrossRef]

10. D'Amato, M.; Laterza, M.; Casamassima, V.M. Seismic performance evaluation of a multi-span existing masonry arch bridge. Open Civ. Eng. J. 2017, 11, 1191-1207. [CrossRef]

11. Tamanna, K.; Raman, S.N.; Jamil, M.; Hamid, R. Utilization of wood waste ash in construction technology: A review. Constr. Build. Mater. 2020, 237, 117654. [CrossRef]

12. Salzer, C.; Wallbaum, H.; Lopez, L.F.; Kouyoumji, J.L. Sustainability of Social Housing in Asia: A Holistic Multi-Perspective Development Process for Bamboo-Based Construction in the Philippines. Sustainability 2016, 8, 151. [CrossRef]

13. Olivier, J.G.J.; Janssens-Maenhout, G.; Muntean, M.; Peters, J.A.H.W. Trends in Global $\mathrm{CO}_{2}$ Emissions. 2016 Report; PBL Netherlands Environmental Assessment Agency: The Hague, The Netherlands, 2016.

14. Ali, N.; Jaffar, A.; Anwer, M.; Alwi, S.K.K.; Anjum, M.N.; Ali, N.; Raja, M.R.; Hussain, A.; Ming, X. The Greenhouse Gas Emissions Produced by Cement Production and Its Impact on Environment: A Review of Global Cement Processing. Int. J. Res. 2015, 2, 488-500.

15. Abu-Jdayil, B.; Mourad, A.; Hittini, W.; Hassan, M.; Hameedi, S. Traditional, state of-the-art and renewable thermal building insulation materials: An overview. Constr. Build. Mater. 2019, 214, 709-735. [CrossRef]

16. United Nations Human Settlements Programme. Sustainable Housing for Sustainable Cities: A Policy Framework for Developing Countries; United Nations Human Settlements Programme: Nairobi, Kenya, 2012.

17. Shanmugam, S.; Sun, C.; Chen, Z.; Wu, Y. Enhanced Bioconversion of Hemicellulosic Biomass by Microbial Consortium for Biobutanol Production with Bioaugmentation Strategy. Bioresour. Technol. 2019, 279, $149-155$. [CrossRef]

18. Khabaz, A. Construction and design requirements of green buildings' roofs in Saudi Arabia depending on thermal conductivity principle. Constr. Build. Mater. 2018, 186, 1119-1131. [CrossRef]

19. Ortiz, O.; Castells, F.; Sonnemann, G. Sustainability in the construction industry: A review of recent developments based on LCA. Constr. Build. Mater. 2009, 23, 28-39. [CrossRef]

20. Arancon, R.N., Jr. The Situation and Prospects for the Utilization of Coconut Wood in Asia and the Pacific; Food and Agriculture Organization of the United Nations regional office for Asia and the Pacific: Bangkok, Thailand, 2009. Available online: http://www.fao.org/3/a-am610e.pdf (accessed on 10 January 2020).

21. Franzini, F.; Toivonen, R.; Toppinen, A. Why NotWood? Benefits and Barriers of Wood as a Multistory Construction Material: Perceptions of Municipal Civil Servants from Finland. Buildings 2018, 8, 159. [CrossRef] 
22. United Nations Environment, International Energy Agency. Towards a Zero-Emission, Efficient, and Resilient Buildings and Construction Sector: Global Status Report 2017; United Nations Environment, International Energy Agency: Nairobi, Kenya, 2017; pp. 1-43. ISBN 978-92-807-3686-1.

23. Toppinen, A.; Röhr, A.; Pätäri, S.; Lähtinen, K.; Toivonen, R. The future of wooden multistory construction in the forest bioeconomy-A delphi study from Finland and Sweden. J. For. Econ. 2018, 31, 3-10. [CrossRef]

24. Kuzman, M.; Lahtinen, K.; Sandberg, D. Initiatives Supporting Timber Constructions in Finland, Slovenia and Sweden. In Proceedings of the IUFRO 2017 Division 5 Conference Forest Sector Innovations for a Greener Future, Vancouver, BC, Canada, 12-16 June 2017.

25. Gosselin, A.; Blanchet, P.; Lehoux, N.; Cimon, Y. Main Motivations and Barriers for Using Wood in Multi-Story and Non-Residential Construction Projects. BioResources 2017, 12, 546-570. [CrossRef]

26. Shen, L.; Yang, J.; Zhang, R.; Shao, C.; Song, X. The Benefits and Barriers for Promoting Bamboo as a Green Building Material in China-An Integrative Analysis. Sustainability 2019, 11, 2493. [CrossRef]

27. Drouin, M. Market Study for Structural Timber in Non-Residential Construction in Quebec; Report No. 301010000; FPInnovations: Quebec City, QC, Canada, 2015.

28. Hurmekoski, E.; Jonsson, R.; Nord, T. Context, drivers, and future potential for wood-frame multi-story construction in Europe. Technol. Forecast. Soc. Chang. 2015, 99, 181-196. [CrossRef]

29. Roth, T.J. Educational Needs Assessment of Designers in West Coast States: Architects and Engineers on the Topic of Wood Products. Master's Thesis, Oregon State University, Corvallis, OR, USA, 2015.

30. ReThinkWood. Tall Wood Takes a Stand; ReThinkWood: Toronto, ON, Canada, 2014.

31. Robichaud, F. The Evolution of Wood Use in Canadian Non-residential Construction; Report No. 301007985; FPInnovations: Quebec City, QC, Canada, 2014.

32. Enjily, V.; Bregulla, J. Barriers to the Enhanced Use of Wood; C.E.I. Bois: Rue Montoyer, Brussels, 2013.

33. Mahapatra, K.; Gustavsson, L.; Hemström, K. Multi-storey wood-frame buildings in Germany, Sweden and the UK. Constr. Innov. 2012, 12, 62-85. [CrossRef]

34. Lehmann, S.; Reinschmi, A.; Mustillo, L. Transition Strategies: Accelerating Social Acceptance and Removing the Barriers to Prefabricated Multi-Storey Timber Urban Infill Developments in Australia Using CLT Construction Systems (PNE293-1213); Forest \& Wood Products Australia: Melbourne, Australia, 2012.

35. FPInnovations. The Use of Wood in Non-Residential Construction in Quebec: Survey of Structural Engineers; Report No. 2001001474; FPInnovations: Quebec City, QC, Canada, 2010.

36. Griffin, C.; Knowles, C.; Theodoropoulos, C.; Allen, J. Barriers to the implementation of sustainable structural materials in green buildings. In Proceedings of the International Conference on Structures \& Architecture, Guimaraes, Portugal, 21-23 July 2010.

37. Manninen, H. Long-Term Outlook for Engineered Wood Products in Europe (Technical Report: 91); European Forest Institute: Joensuu, Finland, 2014.

38. FPInnovations. The Market for Structural Lumber in Non-Residential Construction in Quebec; Report No. 30107433; FPInnovations: Quebec City, QC, Canada, 2013.

39. Nolan, G. Timber in Multi-Residential, Commercial and Industrial Building: Recognising Opportunities and Constraints (PNA140-0809); Forest \& Wood Products Australia: Melbourne, Australia, 2011.

40. Roos, A.; Woxblom, L.; McCluskey, D. The influence of architects and structural engineers on timber in construction-Perceptions and roles. Silva Fenn. 2010, 44, 871-884. [CrossRef]

41. Laguarda, M.M.F.; Espinoza, O. Awareness, perceptions and willingness to adopt Cross-Laminated Timber by the architecture community in the United States. J. Clean. Prod. 2015, 94, 198-210. [CrossRef]

42. Riala, M.; Ilola, L. Multi-storey timber construction and bioeconomy barriers and opportunities. Scand. J. For. Res. 2014, 29, 367-377. [CrossRef]

43. Xia, B.; O'Neill, T.; Zuo, J.; Skitmore, M.; Chen, Q. Perceived obstacles to multi-storey timber-frame construction: An Australian study. Arch. Sci. Rev. 2014, 57, 169-176. [CrossRef]

44. Oliveira, M.; Couto, J.P.; Mendonca, P.; Branco, J.; Silva, M.; Reis, A.P. Low cost construction: State of the art and prospects for using structure wood apartment buildings in Portugal. In Structures and Architecture: Concepts, Applications and Challenges; CRC Press: Boca Raton, FL, USA, 2013; pp. 2168-2175.

45. Knowles, C.; Theodoropoulos, C.; Griffin, C.; Allen, J. Oregon design professionals' views on structural building products in green buildings: Implications for wood. Can. J. For. Res. 2011, 41, 390-400. [CrossRef] 
46. Bhatt, N.; Sarkar, D. Evaluation of success and risk factors for highway project performance through integrated analytical hierarchy process and fuzzy interpretive structural modelling. Int. J. Constr. Manag. 2020, 20, 653-665. [CrossRef]

47. Hedieh Shakeri, H.; Khalilzadeh, M. Analysis of factors affecting project communications with a hybrid DEMATEL-ISM approach (A case study in Iran). Heliyon 2020, 6, 1-18. [CrossRef]

48. Saka, A.B.; Chan, D.W.M. Profound barriers to building information modelling (BIM) adoption in construction small and medium-sized enterprises (SMEs): An interpretive structural modelling approach. Constr. Innov. 2020, 20, 261-284. [CrossRef]

49. Shrivas, A.; Singla, H.K. Analysis of interaction among the factors affecting delay in construction projects using interpretive structural modelling approach. Int. J. Constr. Manag. 2020, 1-9. [CrossRef]

50. Jiang, X.; Lu, K.; Xia, B.; Liu, Y.; Cui, C. Identifying Significant Risks and Analyzing Risk Relationship for Construction PPP Projects in China Using Integrated FISM-MICMAC Approach. Sustainability 2019, 11, 5206. [CrossRef]

51. Sarhan, J.G.; Xia, B.; Fawzia, S.; Karim, A.; Olanipekun, A.O.; Coffey, V. Framework for the implementation of lean construction strategies using the interpretive structural modelling (ISM) technique: A case of the Saudi construction industry. Eng. Constr. Arch. Manag. 2019, 27, 1-23. [CrossRef]

52. Tan, T.; Chen, K.; Xue, F.; Weisheng, L. Barriers to Building Information Modelling (BIM) implementation in China's prefabricated construction: An interpretive structural modelling (ISM) approach. J. Clean. Prod. 2019, 219, 949-959. [CrossRef]

53. Dandage, R.V.; Mantha, S.S.; Rane, S.B. Analysis of interactions among barriers in project risk management. J. Ind. Eng. Int. 2017, 14, 153-169. [CrossRef]

54. Gan, X.; Chang, R.; Zuo, J.; Wen, T.; Zillante, G. Barriers to the transition towards off-site construction in China: An Interpretive structural modelling approach. J. Clean. Prod. 2018, 197, 8-18. [CrossRef]

55. Khan, U.; Haleem, A. Improving to Smart Organization An integrated ISM and fuzzy-MICMAC modelling of barriers. J. Manuf. Technol. Manag. 2015, 26, 807-829. [CrossRef]

56. Rajesh, A.; Dev, N.; Sharma, V. Interpretive structural modelling (ISM) approach: An overview. J. Manag. Sci. 2013, 2, 3-8.

57. Nieves, D.C.; Masegosa, A.D.; Villacorta, P.J.; Novoa, P.; Pelta, D. Improving scenario method for technology foresight by soft computing techniques. In Proceedings of the 4th International Seville Conference on Future-Oriented Technology Analysis (FTA), Sevilla, Spain, 12-13 May 2011. Available online: https: //rb.gy/dcoeca (accessed on 20 February 2020).

58. Naoum, G.S. Dissertation Research and Writing for Construction Students; Routledge: London, UK, 2012. [CrossRef]

59. Enshassi, A.; Mohamed, S.; El Karriri, A. Factors affecting the bid/no bid decision in the Palestinian construction industry. J. Financ. Manag. Prop. Constr. 2010, 15, 118-142. [CrossRef]

60. Kazmi, Z.A.; Sodangi, M. The 2005 Kashmir Earthquake-Devastation of infrastructures. Proc. Inst. Civ. Eng. Struct. Build. 2019, 172, 490-501. [CrossRef]

61. Luthra, S.; Kumar, S.; Kharb, R.; Ansari, M.F.; Shimmi, S.L. Adoption of Smart Grid Technologies: An Analysis of Interactions among Barriers. Renew. Sustain. Energy Rev. 2014, 33, 554-565. [CrossRef]

62. Hwang, B.; Zhao, X.; Yu, G.S. Risk Identification and Allocation in Underground Rail Construction Joint Ventures: Contractors' Perspective. J. Civ. Eng. Manag. 2016, 22, 758-767. [CrossRef]

63. Zhao, X.; Hwang, B.; Low, S.P. Developing Fuzzy Enterprise Risk Management Maturity Model for Construction Firms. J. Constr. Eng. Manag. 2013, 139, 1179-1189. [CrossRef]

64. Ravi, V.; Shankar, R. Analysis of interactions among the barriers of reverse logistics. Technol. Forecast. Soc. Chang. 2005, 72, 1011-1029. [CrossRef]

(C) 2020 by the authors. Licensee MDPI, Basel, Switzerland. This article is an open access article distributed under the terms and conditions of the Creative Commons Attribution (CC BY) license (http://creativecommons.org/licenses/by/4.0/). 